3

\title{
Tennis Service Performance in Beginners: The Effect of Instructional Self-talk
}

Combined with Motor Imagery

(1)

Nicolas Robin ${ }^{1}$, Robbin $_{\text {Carien }}{ }^{1}$, and Laurent Dominique ${ }^{2}$

${ }^{1}$ Université des Antilles, Laboratoire "Adaptation au Climat Tropical, Exercice \& Santé",

Faculté des Sciences du Sport de Pointe-à-Pitre, France. Tel +33 590483 173; Fax +33 590

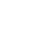
483179

${ }^{2}$ Université de la Réunion, Laboratoire ACTES, France

\begin{abstract}
Correspondence concerning this article should be addressed to Nicolas Robin, Laboratoire
\end{abstract} "Adaptation au Climat Tropical, Exercice \& Santé" (UPRES EA 3596), Campus Fouillole, BP 592, 97159, Pointe à Pitre Cedex, France.

Contact: robin.nicolas@hotmail.fr

Declarations of interest: None.

6 Declarations of interest: None. 


\section{Abstract}

2 The aim of this study was to investigate the effect of motor imagery (MI) combined with

3 instructional self-talk on service performance in young novice tennis players. The participants

4 were assigned to one of three groups: Control, MI or MI+self-talk. They performed a pre-test

5 (10 services), participated in 5 days of intervention sessions, and finally performed a post-test

6 similar to the pre-test. During the intervention sessions, the participants performed 20

7 services. The Control group was not given any instructions other than verbal instructions on

8 the steps of the serve. Before each service, the MI group was instructed to imagine

9 performing a successful service towards the "correct" service box. The MI+self-talk group

10 had to repeat the instructions during MI, before serving. The results of this original study

11 revealed that only the participants in the MI and MI+self-talk groups increased their service

12 percentage of success and technical quality scores from pre- to post-test. In addition, at post-

13 test, the participants of the MI+self-talk group had higher serve speeds and technical quality

14 scores than the participants of the Control and MI groups. The beneficial effect of using MI

15 and/or self-talk during short tennis interventions and the practical applications are discussed.

16 Key words: Tennis service, motor imagery, self-talk, performance, novice. 


\section{Tennis Service Performance in Beginners: The Effect of Instructional Self-talk}

\section{Combined with Motor Imagery}

According to Cece et al. (2020), the beneficial effects of using mental training

techniques as strategies to improve motor learning and performance are widely acknowledged by coaches, mental trainers and players, especially in racket sports. Among these techniques, motor imagery (MI) seems to be the most frequently used technique, especially by tennis players regardless of their level of expertise (Dominique et al., in press; Mamassis, 2005). MI can be defined as a conscious process that requires mentally simulating an action without executing it (Robin et al., 2007). Numerous studies have shown that using MI in addition to physical training promotes motor learning and performance in sport (Schuster et al., 2011; Simonsmeier et al., 2020) and more specifically in tennis (Cherappurath \& Elayaraja, 2017; Dana \& Gozalzadeh, 2017; Fekih et al., 2020; Hegazy et al., 2015; Turan et al., 2019). For example, Guillot et al. (2013) showed that young tennis players had higher service performance (i.e., accuracy, speed and percentage of success) after MI interventions than in a control condition. In addition, other studies have shown the beneficial effects of using a combination of mental techniques, such as MI and self-talk, in tennis mental training programs to improve players' performances (Coelho et al., 2007; Dohme et al., 2020; Gabr, 2010; Morais \& Rui Gomes, 2019).

Self-talk mainly refers to covert verbalizations that athletes address to themselves (Latinjak et al., 2019). Several studies support its effectiveness in sports (for a review, see Hardy, 2006). According to Theodorakis et al. (2000), self-talk can fulfil at least two functions: Motivational (i.e., discourse on self-confidence, increasing effort, optimizing the energy deployed or promoting a positive mood) and cognitive (e.g., verbalizations with an attentional focus directed towards technique and movements to perform). Van Raalte et al. (2016) pointed out that it is important to distinguish between spontaneous or uncontrolled 
1 self-talk, which concerns statements related to the activities that come to mind spontaneously

2 and effortlessly and concern past or future outcomes, and strategic or goal-directed self-talk,

3 which is a deliberate strategy that players employ to regulate emotions by means of its

4 motivational function (Fritsch et al., 2020) or to enhance performance by means of its

5 cognitive function (Boudreault et al., 2016). Indeed, cognitive self-talk, also called

6 instructional self-talk (Latinjak et al., 2011), can promote performance by focusing athletes'

7 attention on technique (e.g., toss, backswing, contact and follow-through for a service) or the

8 motor actions that need to be performed (e.g., "getting back on the court"). In a water polo

9 task requiring precision, Hatzigeorgiadis et al. (2004) showed that instructional self-talk had a

10 higher impact on performance than motivational self-talk or a control condition. More

11 specifically in tennis, Landin and Hebert (1999) found among experienced players that

12 instructional self-talk increased movement patterns or accuracy and helped gain and maintain

13 concentration when they performed volley shots. Similarly, Cutton and Landin (2007) showed

14 the beneficial effects of using self-talk on learning the forehand tennis groundstroke during

15 beginning tennis classes. Indeed, directing players to the critical parts of a motor skill can be

16 facilitated by instructional self-talk (Hardy et al., 2001), especially in beginners (Magill,

17 2004), and can facilitate motor learning and performance improvement (Boudreault et al., 18 2016).

Previous studies have supported instructional self-talk as an effective tool for skill

20 acquisition and performance improvement in novice tennis players making volley shots

21 (Cutton \& Landin, 2007) or skilled players performing services (Malouff et al., 2008). The

22 latter authors and others have also reported that MI interventions have beneficial effects on

23 tennis movement accuracy and performance (e.g., Cherappurath et al., 2020; Guillot et al.,

24 2013) and that a combination of MI and self-talk can enhance motor performance in a

25 precision task (Cumming et al., 2006). This has therefore been recommended during pre- 
1 motor execution in tennis (Morais et al., 2019). Given these findings, the aim of this original

2 study was to evaluate the effects of a combination of instructional self-talk and MI on service

3 performance in beginners. In novice players who are not familiar with MI, especially in

4 tennis, self-talk related to the steps in performing a service might facilitate the creation or use

5 of a mental representation of the movement requested during imagery (Schack et al., 2014).

6 Moreover, Fitts and Posner (1967) noted that during early learning stages (i.e., the cognitive

7 stage), novices tend to "talk" themselves through movements, and instructional self-talk could

8 provide appropriate content for this inner dialogue (Hardy et al., 2009) during both real and

9 imagined movements. Based on the results of the above-mentioned research, we hypothesized

10 that using MI in addition to physical practice would result in higher performances than

11 physical practice alone (i.e., control condition) in novice tennis players. We also hypothesized

12 that the use of instructional self-talk combined with MI would increase performances even 13 more than the MI intervention and a control condition.

\section{Methods}

\section{Participants}

Thirty-eight novice tennis players $\left(M_{a g e}=9.59, S D=3.24\right)$ volunteered to participate in this study that was conducted according to the guidelines of the Declaration of Helsinki. All the participants had no more than 1 year of tennis practice. The current study was consistent with the ethical principles specified in the APA standards and was approved by the local ethics committee of the University. The participants who volunteered to participate in the study, as well as their parents, were given details about what their involvement would consist of and were assured about their right to withdraw. They were also provided with a consent form describing the study aim and procedure and gave their written consent. Standard verbal and written instructions regarding the content of the protocol were then provided. 
1 Instructions emphasized the confidentiality of the results. The participants were randomly

2 assigned to one of three groups: Control, $(N=13), \mathrm{MI}(N=12)$ and MI+self-talk $(N=13)$.

\section{Study Design}

4

The study used a pre-post experimental design and was carried out during a 5-day daily tennis course. All the participants performed a pre-test, then four sessions of practice, and then a post-test. The pre-test and the first practice session were performed on day 1 , the second to fourth practice sessions from day 2 to day 4 , and the post-test on day 5 .

\section{Material}

The experimental task was carried out on a tennis court meeting the international standards. Each experimental session was held at the same time of day (9 am) for all conditions to avoid circadian effects.

\section{Outcome, Measure and Task}

Service test. During the pre- and post-tests, all the participants performed 10 services as accurately as possible using intermediate service balls. Performance was evaluated in terms of percentage of success (i.e., bounce of the ball in the service box), serve speed (recorded by means of a Cordless MPH Radar Gun, Type R1000), and technical quality (mean scores on 6 items: Starting position, ball throw, arm-racket movement backwards, arm-racket movement forward, point of contact and end of movement, noted with a scale ranging from 0: poor to 7: excellent) for each service. These evaluations were made afterward by two qualified expert tennis coaches via videos (for a similar procedure, see Atienza et al., 1994). The performances of the participants were filmed with two Canon HD, Legria HF G25 cameras during the preand post-tests. The two cameras were placed, respectively, to the right and to the left in the extension of the baseline, 4 meters from the doubles sideline.

Mental task. Participants in the Control group performed a mental task: Countdown, which corresponded approximately to the length of time (about 10 seconds) that the 
1 participants from the other groups spent on MI (for a similar procedure, see Robin et al.,

2 2019), before each actual service. The instructions were "Position yourself to serve behind the

3 baseline. Close your eyes. You are going to count down from 10 to 0 at the rate of one

4 number per second."

Motor imagery task. The MI was performed on the tennis court. Participants in the

MI and MI+self-talk groups were instructed to imagine performing a service using an external visual modality (i.e., seeing themselves in the third person, as if they were being filmed with a camera) and seeing the service box they wanted to reach (for a similar procedure, see Guillot et al., 2013) before they actually served. An MI script was read to the participants at the beginning of each intervention session to ensure that they received similar instructions: "Position yourself to serve behind the baseline. Close your eyes. You are going to visually imagine yourself, as if you were being filmed with a camera, performing a successful service toward the correct service box by visualizing each of the steps of the movement." As indices of imagery quality, the participants self-reported the level of perceived vividness on a Likert scale ranging from 1 ("Unclear and inaccurate mental representation") to 6 ("Perfectly clear and vivid mental representation") (for a similar procedure, see Dominique et al., in press). Self-talk and imagery. Participants of the MI+self-talk group had to perform MI combined with instructional self-talk using a script based on the steps of a serve (i.e., starting position, ball throw, arm-racket movement backwards, arm-racket movement forward, point of contact and end of movement) before performing a service and not during actual service.

21 The instructions were: "Position yourself to serve behind the baseline. Close your eyes. You are going to visually imagine yourself, as if you were being filmed with a camera, performing a successful service toward the correct service box by visualizing each of the steps of the movement. You must combine the mental images with self-talk concerning your starting 
1 position, the ball throwing, the arm-racket backwards then forward movements, the contact of

2 the ball in the centre of your racket, and the end of your movement."

3 the pre-test. The duration of these two phases was approximately 25 minutes.

\section{Procedure}

Before the start of the study, the experimenters met with the tennis players to determine their knowledge about MI. They were questioned about the frequency and nature of their imagery use in order to exclude the participants who were totally unfamiliar with MI (see Guillot et al., 2013, for a similar procedure). The participants self-reported using visual imagery more easily and frequently than the other MI modalities.

Pre-test phase. During the pre-test held on day 1, participants performed a standardized 20-minute warm-up and then performed 10 services by alternating the service box after each trial.

Intervention phase. After the pre-test and on the four following days, the participants performed serves in the four sessions composing the intervention phase. Each session started with a standardized 20-minute warm-up. Then the participants had to serve 20 times by alternating the service box after each trial. The participants of the Control group were not given any instructions other than verbal instructions on the steps of the serve. Those of the MI group were instructed to use MI (i.e., to imagine, from a third person perspective, performing a successful service towards the "correct" service box) before each real service execution. Finally, the participants in the MI+self-talk group had to repeat the instructions during MI, before each service. The duration of each session was approximately 30 minutes for all groups.

Post-test phase. On day 5, the participants performed a post-test that was identical to 24 Data Analysis 
First, the MI quality scores across the experimental groups who performed MI were examined. The percentage of success, speed of successful services, and technical quality scores regarding the service balls served as dependent variables and indicators of performance during the pre- and post-tests. For the technical quality scores, a third expert (i.e., last author) was consulted when disagreements arose in order to obtain a single score. Normality was checked (Kolmogorov-Smirnov test) and the dependent variables were submitted to 3 Group (Control vs. MI vs. MI+self-talk) x 2 Phase (pre-test vs. post-test) ANOVAs with repeated measures on the second factor. Effect sizes $\left(\eta_{\mathrm{p}}{ }^{2}\right)$ were indicated, $\alpha$ was set at .05 for all analyses, and post hoc tests were performed using Newman-Keuls tests.

\section{Results}

Imagery Quality and Descriptive Results

The results for the imagery quality scores revealed that no participant reported difficulty performing MI, and no difference was found between groups when we compared the quality scores in the MI $\left(M_{\text {score }}=4.15, S D=0.75\right)$ and MI+self-talk $\left(M_{\text {score }}=4.72, S D=\right.$ $0.93)$ groups $\left[t(23)=-0.93, p=.15, \eta_{\mathrm{p}}^{2}=0.02\right]$.

\section{Percentage of Success of the Service}

The results for the percentage of successful serves revealed an absence of difference between the Control, MI and MI+self-talk groups when considered independently of the experimental phases. Indeed, the ANOVA computed on the percentage of success revealed no

significant main group effect $\left[F(2,35)=1.25, p=.29, \eta_{\mathrm{p}}{ }^{2}=0.06\right]$. However, differences were observed not only between the performances obtained during the pre-test and post-test in all groups, but also between the post-test results of the three groups. Indeed, the analysis revealed

23 a significant main phase effect $\left[F(1,35)=74.41, p=.001, \eta_{\mathrm{p}}{ }^{2}=0.68\right]$ and an interaction 24 between group and phase $\left[F(2,35)=21.72, p=.001, \eta_{\mathrm{p}}{ }^{2}=0.55\right]$. As illustrated in Figure 1a, the MI and MI+self-talk groups increased their performances from pre- to post-test and had 
1 higher performances at the post-test than the participants of the Control group, whose

2 performance remained stable $(p s<.01)$.

3

Figure 1 near here

\section{Serve Speed}

The results for the serve speed of the successful services revealed an absence of difference between the Control, MI and MI+self-talk groups when considered independently of the experimental phases. Indeed, the ANOVA computed on serve speed revealed no significant main group effect $\left[F(2,35)=0.58, p=.56, \eta_{\mathrm{p}}{ }^{2}=0.03\right]$. However, differences were observed not only between the performances obtained during the pre-test and post-test for all groups, but also but also between the post-test results of the three groups. Indeed, the analysis revealed a significant main phase effect $\left[F(1,35)=22.71, p=.001, \eta_{\mathrm{p}}{ }^{2}=0.40\right]$ and an interaction between group and phase $\left[F(2,35)=13.46, p=.001, \eta_{\mathrm{p}}{ }^{2}=0.44\right]$. As illustrated in Figure $1 \mathrm{~b}$, only participants in the MI+self-talk group increased their performance from preto post-test $(p<.01)$.

\section{Technical Quality}

The results for the technical quality scores revealed an absence of difference between the Control, MI and MI+self-talk groups when considered independently of the experimental phases. Indeed, the ANOVA computed on technical quality revealed no significant main group effect $\left[F(2,35)=2.37, p=.11, \eta_{\mathrm{p}}{ }^{2}=0.11\right]$. However, differences were observed not only between the performances obtained during the pre-test and post-test for all groups, but also between the post-test results of the three groups. Indeed, the analysis revealed a significant main phase effect $\left[F(1,35)=17.52, p=.001, \eta_{\mathrm{p}}{ }^{2}=0.34\right]$ and an interaction between group and phase $\left[F(2,35)=5.06, p=.05, \eta_{\mathrm{p}}{ }^{2}=0.23\right]$. As illustrated in Figure $1 \mathrm{c}$, the 
1 MI and MI+self-talk groups increased their performances from pre- to post-test $(p s<.01)$.

2 Finally, the participants of the MI+self-talk group had higher performances at the post-test 3 than the participants of the Control and MI groups $(p s<.01)$.

\section{Discussion}

The aim of this study was to evaluate the effect of motor imagery practice combined or not with instructional self-talk on the performance of novice tennis players performing services during a 5-day intervention.

As hypothesized, the results of the study first show that the participants in the MI groups, who performed motor imagery before the actual practice of the service, had a higher percentage of successful performances than the participants in the Control group, who had no instructions other than those concerning the steps to be taken for the serve. These results are consistent with those of previous studies that have shown the beneficial effects of using MI interventions in experienced (e.g., Dominique et al., in press; Cherappurath et al., 2020), nonexpert (e.g., Atienza et al., 1998; Dana \& Gozalzadeh, 2017; Fekih et al., 2020; Guillot et al., 2012) and novice (e.g., Féry et al., 2000; Noel, 1980) tennis players. Moreover, as in the study by Guillot et al. (2013), the results of this experiment highlight the positive effects of using an external visual MI practice in combination with physical practice for beginners. They are also in line with previous studies that have shown that external visual imagery is effective for form-based movement because players can easily visualize the overall positions and movements necessary for a successful performance (Hardy \& Callow, 1999; White \& Hardy, 1995). Finally, the present study provides further support for practising MI on the tennis court while wearing sports clothing and handling the racket (Guillot et al., 2005) and offers some additional practical applications to coaches and players about using imagery, especially to improve motor learning and performance in novice tennis players. 
1 with MI before serving significantly increased their percentage of success, serve speed and

2 technical quality scores from pre- to post-test and had higher technical quality scores than the

3 participants in the Control and MI groups. It is also important to note that the MI+self-talk

4 group was the only one to increase the serve speed. These results are consistent with those of

5 studies that have shown the beneficial effects of combining different mental strategies with

6 actual practice (e.g., MI and self-talk) to improve motor performance in tennis (Mamassis \&

7 Doganis, 2004; Dohme et al., 2020). In addition, these results seem to show the beneficial

8 effect of the cognitive function of instructional self-talk in novice tennis players (Boudreault

9 et al., 2016; Hatzigeorgiadis et al., 2004; Latinjak et al., 2011), especially when it is combined

10 with MI (Dohme et al., 2020). Overall, these results demonstrate the beneficial effects of self-

11 talk on athlete performance (Hardy, 2006) even among beginners (e.g., Latinjak et al., 2018),

12 who tend to talk themselves through the phases of a movement (Fitts \& Posner, 1967). As

13 previously noted by Landin and Hebert (1999), we might assume that the instructional self-

14 talk helped the participants to gain and maintain concentration during MI. Moreover, directing

15 novice tennis players to pay attention by using self-talk in order to appropriate cues when

16 learning a complex motor skill like the service should be encouraged for its instructional

17 purpose (Hardy et al., 2001), as it notably decreases interfering thoughts (Cutton \& Landin,

18 2007) and/or improves the effective storage and retrieval of relevant task information (Singer,

19 2000). We might also consider that self-talk helps participants to imagine the critical parts of

20 the service (e.g., ball throw, arm-racket movement backwards, arm-racket movement forward,

21 point of contact or end of movement) during MI, which would give them an advantage over

22 participants who only use MI. Indeed, the participants of the MI+self-talk group had higher

23 MI quality scores than the participants of the MI group, although the difference was not

24 statistically significant. Additional research that includes other techniques like mental

25 chronometry might explore this hypothesis. 
This study is not without limitations. The absence of a self-talk-only condition could

2 be considered a limitation. Indeed, although all the tennis players who benefited from MI (i.e.,

3 MI and MI+self-talk groups) increased their performances, with a greater effect for those who

4 used a combination of self-talk and MI, an instructional self-talk-only condition might also be

5 beneficial or even optimal. In addition, although the participants of the MI and MI+self-talk

6 groups declared that they had performed MI and MI+self-talk, respectively, during the

7 intervention phase, we do not know if they or the participants of the Control group used self-

8 talk during the actual service. Finally, the participants of the Control group may have been

9 less motivated than those of the other groups due to the experimental conditions. More

10 research is needed to confirm the results obtained in the current study, particularly by

11 controlling the use of self-talk during actual service, and to evaluate the effect of instructional

12 self-talk only and the motivation of the participants. In light of the results obtained in this

13 study, we recommend that coaches use a combination of MI and self-talk directly on the court

14 to promote the learning of complex motor tasks, such as serving in tennis.

\section{Conclusion}

The objective of this study was to assess the effect of a combination of motor imagery and instructional self-talk over a 5-day intervention on the performance of novice tennis players practising the service. The results showed a beneficial effect of using motor imagery before actual service and showed further improvement when imagery was combined with self-talk. These results have ecological implications for novice and non-expert tennis players. Indeed, the service is a complex but crucial skill with a determining role for engaging and winning points during matches. The results seem to indicate that instructional self-talk can be an additional tool in the hands of coaches to improve learning and performance.

\section{References}

Atienza, F. L., Balaguer, I., \& García-Merita, M. L. (1998). Video modeling and imaging 
training on performance of tennis service of 9- to 12-year-old children. Perceptual and Motor Skills, 87(2), 519-529.

Boudreault, V., Trottier, C. \& Provencher, M. (2016). Self-talk in sport : A critical review. Staps, 111, 43-64. https://doi.org/10.3917/sta.111.0043

Cece, V., Guillet-Descas, E., \& Martinent, G. (2020). Mental training program in racket sports: A systematic review. International Journal of Racket Sports Science, 2(1), 5571.

Cherappurath, N., \& Elayaraja, M. (2017). Combined effects of SAQ and PETTLEP imagery training: A study on the learning process of new skills among novice tennis players. International Journal of Physical Education Sports and Health, 2, 169-173.

Cherappurath, N., Elayaraja, M., Kabeer, D. A., Anjum, A., Vogazianos, P., \& Antoniades, A. (2020). PETTLEP imagery and tennis service performance: an applied investigation, Journal of Imagery Research in Sport and Physical Activity, 15(1), 20190013. https://doi.org/10.1515/jirspa-2019-0013

Coelho, R. W., De Campos, W., Silva, S. G. D., Okazaki, F. H. A., \& Keller, B. (2007). Imagery intervention in open and closed tennis motor skill performance. Perceptual and Motor Skills, 105(2), 458-468. https://doi.org/10.2466/pms.105.2.458-468

Cumming, J., Nordin, S. M., Horton, R., \& Reynolds, S. (2006). Examining the Direction of Imagery and Self-Talk on Dart-Throwing Performance and Self Efficacy. The Sport Psychologist, 20(3), 257-274. https://journals.humankinetics.com/view/journals/tsp/20/3/article-p257.xml

Cutton, D., \& Landin, D. (2007). The Effects of Self-Talk and Augmented Feedback on Learning the Tennis Forehand. Journal of Applied Sport Psychology, 19(3), 288303. https://doi.org/10.1080/10413200701328664

Dana, A., \& Gozalzadeh, E. (2017). Internal and external imagery effects on tennis skills 
among novices. Perceptual and Motor Skills, 124(5), 1022-1043. https://doi.org/10.1177/0031512517719611

Dohme, L.-C., Bloom, G. A., Piggott, D., \& Backhouse, S. (2020). Development, implementation, and evaluation of an athlete- informed mental skills training program for elite youth tennis players. Journal of Applied Sport Psychology, 429-449.

Dominique, L., Coudevylle, G., \& Robin, N. (in press). Effet d'une routine centrée sur l'imagerie mentale et sur l'efficacité du service chez des joueurs de tennis experts. Staps. https://doi.org/10.3917/sta.pr1.0027

Fekih, S., Zguira, M. S., Koubaa, A., Masmoudi, L., Bragazzi, N. L., \& Jarraya, M. (2020). Effects of motor mental imagery training on tennis service performance during the ramadan fasting: a randomized, controlled trial. Nutrients, 12(4), 1035. https://doi.org/10.3390/nu12041035

Féry, Y. A., \& Morizot, P. (2000). Kinesthetic and visual images in modelling closed motor skills: the example of the tennis serve. Perceptual and Motor Skills, 90, 707-722.

Fitts, P. M., \& Posner, M. I. (1967). Human performance. Belmont, CA: Brooks/Cole.

Fritsch, J., Jekauc, D., Elsborg, P., Latinjak, A.T., Reichert, M., \& Hatzigeorgiadis, A. (2020). Self-talk and emotions in tennis players during competitive matches. Journal of Applied Sport Psychology, 1-21.

Gabr, W. A. (2010). Mental imagery and self-talk as approach to cope with pressure among individual sports. World Journal of Sport Sciences, 3(S), 104-108.

Guillot, A., Collet, C., \& Dittmar, A. (2005). Influence of environmental context on motor imagery quality: An automatic nervous system study. Biology of Sport, 22, 215-226.

Guillot, A., Desliens, S., Rouyer, C., \& Rogowski, I. (2013). Motor imagery and tennis serve performance: The external focus efficacy. Journal of Sports Science \& Medicine, 12(2), 332-338. 
1 Hardy, J. (2006). Speaking clearly: A critical review of the self-talk literature. Psychology of Sport and Exercise, 7(1), 81-97. https://doi.org/10.1016/j.psychsport.2005.04.002.

Hardy, L., \& Callow, N. (1999) Efficacy of external and internal visual imagery perspectives for the enhancement of performance on tasks in which form is important. Journal of Sport and Exercise Psychology, 21, 95-112.

Hardy, J., Gammage, K., \& Hall, C. R. (2001). A description of athlete's self-talk. The Sport Psychologist, 15, 306-318. https://doi.org/10.1016/S1469-0292(01)00011-5

Hardy, J., Oliver, E., \& Tod, D. (2009). A framework for the study and application of self-talk within sport. In S.D. Mellalieu \& S. Hanton (Eds.), Advances in applied sport psychology: A review (pp. 37-74). London: Routledge.

Hatzigeorgiadis, A., Theodorakis, Y., \& Zourbanos, N. (2004). Self talk in the swimming pool: The effects of self talk on thought content and performance on waterpolo tasks. Journal of Applied Sport Psychology, 16, 138-150. https://doi.org/10.1080/10413200490437886

Hegazy, K., Sherif, A., \& Houta, S. (2015). The effect of mental training on motor performance of tennis and field hockey strokes in novice players. Advances in Physical Education, 5, 77-83.

Landin, D., \& Hebert, E. P. (1999). The influence of self talk on the performance of skilled female tennis players. Journal of Applied Sport Psychology, 11, 263-282.

Latinjak, A. T., Hernando-Gimeno, C., Lorido-M_endez, L., \& Hardy, J. (2019). Endorsement and constructive criticism of an innovative online reflexive self-talk intervention. Frontiers in Psycholology 10, 1819. doi: 10.3389/fpsyg.2019.01819.

Latinjak, A.T., Masó, M., \& Comoutos, N. (2017). Goal-Directed Self-Talk Used During Technical Skill Acquisition: The Case of Novice Ultimate Frisbee Players. The Sport Psychologist, 32, 60-65. 
1 Latinjak, A. T., Torregrosa, M., \& Renom, J. (2011). Combining self talk and performance feedback: their effectiveness with adult tennis players. The Sport Psychologist, 25(1), 18-31. http://dx.doi.org/10.1123/tsp.25.1.18

Magill, R. (2004). Motor learning and control: Concepts and applications. New York: McGraw-Hill.

Malouff, J. M., McGee, J. A., Halford, H. T., \& Rooke, S. E. (2008). Effects of precompetition positive imagery and self-instruction on accuracy of serving in tennis. Journal of Sport Behaviour, 31, 264-275.

Mamassis, G. (2005). Improving serving speed in young tennis players. ITF Coaching and Sport Science Review, 35, 3-4.

Mamassis, G., \& Doganis, G. (2004). The effects of a mental training program on juniors precompetitive anxiety, self-confidence, and tennis performance. Journal of Applied Sport Psychology, 16(2), 118-137. https://doi.org/10.1080/10413200490437903

Morais, C., \& Rui Gomes, A. (2019). Pre-service routines, mental toughness and performance enhancement of young tennis athletes. International Journal of Sport Psychology, 50, 176-192. https://doi.org/10.7352/IJSP.2019.50.176

Noel, R. C. (1980). The effect of visuo-motor behavior rehearsal on tennis performance. Journal of Sport Psychology, 2(3), 221-226. https://doi.org/10.1123/jsp.2.3.221

Robin, N., Toussaint, L., Charles-Charlery, C., \& Coudevylle, G.R. (2019). Free Throw Performance in Intermediate Basketball Players: The Effect of Dynamic Motor Imagery with and without a Video of a Model. Learning and Motivation, 68.

Robin, N., Dominique, L., Toussaint, L., Blandin, Y., Guillot, A., \& Le Her, M. (2007). Effects of motor imagery training on service return accuracy in tennis: The role of imagery ability. International Journal of Sport and Exercise Psychology, 5, 175-186. https://doi.org/10.108 0/1612197X.2007.9671818 
1 Schack, T., Essig, K., Frank, C., \& Koester, D. (2014). Mental representation and motor imagery training. Frontiers in human neuroscience, 8, 328. https://doi.org/10.3389/fnhum.2014.00328

Schuster, C., Hilfiker, R., Amft, O., Scheidhauer, A., Andrews, B., Butler, J., ... \& Ettlin, T. (2011). Best practice for motor imagery: A systematic literature review on motor imagery training elements in five different disciplines. BMC Medicine, 9, 75. https://doi.org/10.1186/1741-7015-9-75

Simonsmeier, B., Androniea, M., Buecker, S., \& Frank, C. (2020). The effects of imagery interventions in sports: a meta-analysis. International Review of Sport and Exercise Psychology, https://doi.org/10.1080/1750984X.2020.1780627

Singer, R. N. (2000). Performance and human factors: considerations about cognition and attention for self-paced and externally paced events.. Ergonomics, 43(10), 16611680.

Theodorakis, Y., Weinberg, R., Natsis, P., Douma, I., \& Kazakas, P. (2000). The effects of motivational versus instructional self-talk on improving motor performance. The Sport Psychologist, 14, 253-271. https://doi.org/10.1123/tsp.14.3.253d

Turan, M., Dişçeken, O., \& Kaya, M. (2019). The impact of cognitive-based learning and imagery training on tennis skills. Universal Journal of Educational Research, 7, 244249.

Van Raalte, J. L., Vincent, A., \& Brewer, B. W. (2016). Self-talk: Review and sport-specific model. Psychology of Sport and Exercise, 22, 139-148.

White, A., \& Hardy, L. (1995). Use of different imagery perspectives on the learning and performance of different motor skills. British Journal of Psychology, 86(2), 169-180. 
1 We greatly appreciate the considerable time and effort of Cristophe Boudier, tennis coach at

2 the Amicale Tennis Club, and the subjects who participated in this project.

3

4

5

6

7

8

9

10

11

12

13

14

15

16 

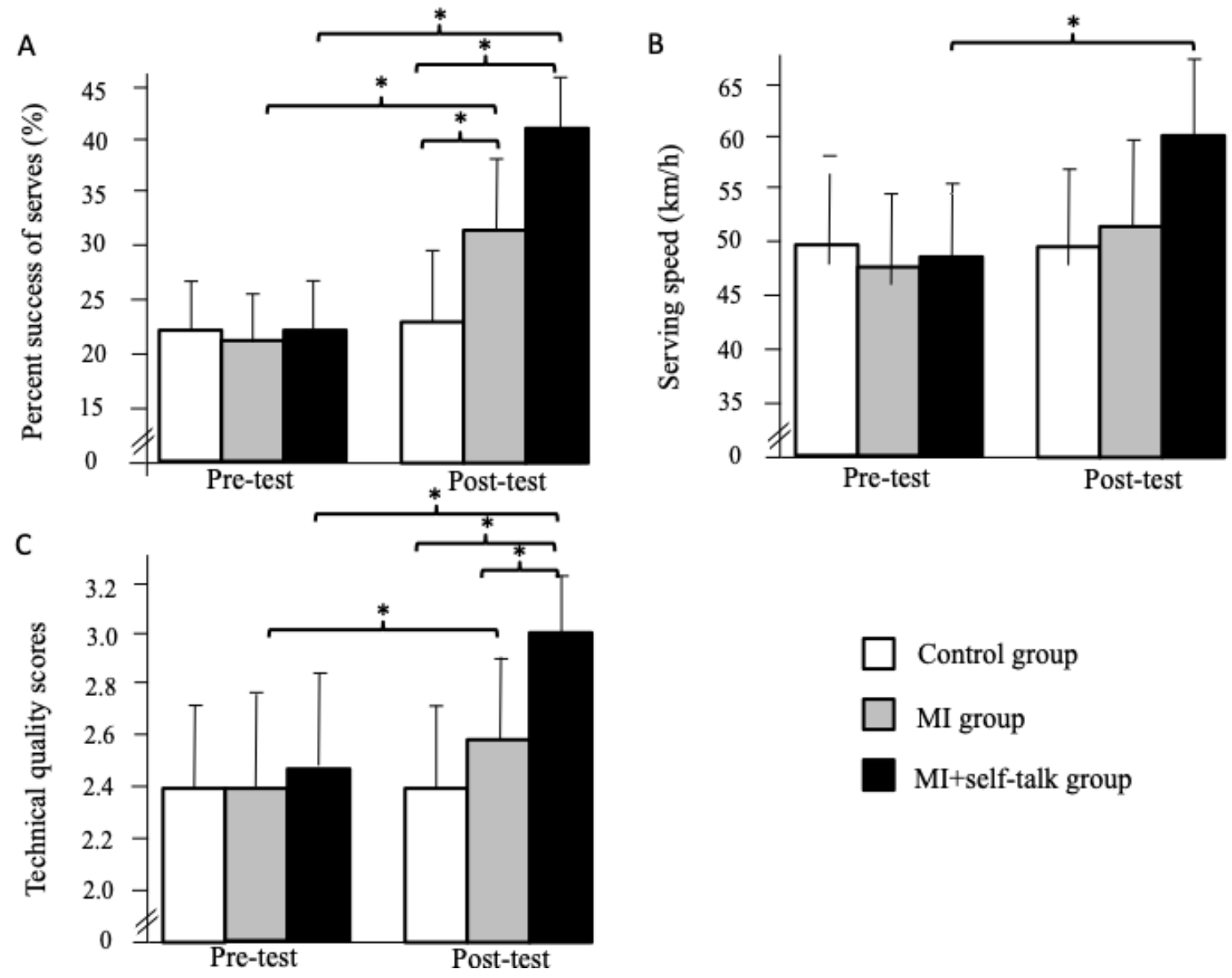

2 Figure 1. Significant interaction between the group (MI vs. MI+self-talk vs. Control) and the

3 phase (pre-test vs. post-test) concerning the percentage of service success (A), the speed serve

4 (B), and the technical quality scores $(\mathrm{B}),\left({ }^{*} p<.01\right)$ 